\title{
The Development of English Competency-Based Curriculum Integrated with Local Community for High School Students
}

\author{
Goachagorn Thipatdee ${ }^{1}$ \\ ${ }^{1}$ Ubon Ratchathani Rajabhat University, Ubon Ratchathani, Thailand \\ Correspondence: Goachagorn Thipatdee, Ubon Ratchathani Rajabhat University, Ubon Ratchathani, Thailand. \\ E-mail: goat@ubru.ac.th
}

Received: October 19, 2020 Accepted: December 12, 2020 Online Published: December 30, 2020

doi:10.5539/jel.v10n1p39 URL: https://doi.org/10.5539/jel.v10n1p39

\begin{abstract}
The purposes of this research were to study needs of high school students and teachers on competency-based curriculum integrated with local community for high school students, develop a curriculum based on the needs, implement the developed curriculum, and evaluate the developed curriculum. The samples of the needs study stage consisted of 244 high school students, and 82 teachers in schools located in Ubon Ratchathani, and Warinchamrab Municipalities, gained by quota sampling, and those for the curriculum implementation consisted of 34 high school students studying at Luekamhan Warinchamrab School, in the second semester of academic year 2018, gained by cluster sampling. The research instruments were the developed curriculum, questionnaires for the students and the teachers, a test of English expression, a test of writing, and an attitude evaluation form. The findings revealed the students and the teachers rated their needs on competency-based curriculum at a higher level, the developed curriculum consisted of vision, mission to achieve the students' competency through the aims, contents, and instructional procedures concentrated on practicing and the evaluation focused on performances, the students had significantly higher learning achievement and writing skills after the curriculum implementation than those before the implementation at the level .01. The developed curriculum was evaluated by the students at medium level of its feasibility.
\end{abstract}

Keywords: English competency-based curriculum, local community, high school

\section{Introduction}

The basic education curriculum implementation based on the Educational Act of 1999 in Thailand has occurred some problems in different aspects. In the aspect of curriculum implementation, or the teaching learning process, the most serious problem was that the teachers used teacher-centered method of teaching, which needed to be shifted. Therefore, the Office of the Education Council (2008) conducted a research in collaboration with 586 master teachers across the country aimed to develop 8,848 teachers, as the network members. The findings revealed that the network members were able to adapt 9 techniques of the learner centered namely questioning techniques, problem solving techniques, problem-based instruction, generation of knowledge through constructivism, promotion of constructive thinking, project-based learning, using of authentic experience, integration of multiple intelligences, and using of learning sources in local communities. Nearly a decade passed however, there had still occurred several problems concerning the curriculum implementation as identified by the empirical data based on research results conducted by Nillapun et al. (2015), which found the basic education core curriculum 2008 cannot reflect the good quality of the students, the administrators and teachers lacked of knowledge and understanding on the curriculum administration in aspects of designing processes for teaching, techniques of authentic assessment, and social and public activity evaluation.

The designing process for teaching, and the techniques of authentic assessment, in general, were not separated in practicing through the process of a curriculum implementation since they needed to be combined as the steps of competency oriented instruction, as specified by Nikolov et al. (2014) that the process begins through the competence definition on the objective, the designing of competence behaviors associated with learning activities on the process of learning, the competence behaviors used as measurable indicators of learning progress on the assessment, and the learning outcome is the extent to which the competence is acquired. Therefore, a teacher who applies the competency-based instruction needs to continually follow the steps to be successful in practicing this learner centered method. 
Learning outcomes, based on the competency-based curriculum implementation consisted of three aspects of knowledge, skills, and attitude as identified by Chambers (1993) that competencies are skills combined appropriate supporting knowledge and attitude, and they are performed reliably in natural settings without assistance. In addition, Andronache et al. (2015) deliberately defined that conceptual structural elements of competencies are; knowledge, defined as the result of assimilation by learning information, facts, concepts and theories through an abstraction process; skills, referred to the ability to apply and use in practice acquired knowledge, solve problems, and achieve various tasks; and attitudes, defined in specialized literature, especially in the works of social psychology, considering favorable or unfavorable, and therefore showing a certain behavior, opinions as a mental and neurophysiological state determined by experience, and which exerts a dynamic influence on an individual to act in a specific way. Therefore, it may be concluded that to acquire a competence, an individual needs to practice a favorable task skillfully with appropriate knowledge concerning it.

Contexts of each school, or local communities can be used as meaningful learning sources for students because the contents will be easy to learn, interesting, and have great deal of meanings to their life, as the Answer Programs (2020) described that the community-based curriculum dedicated to service learning, exploring new ideas, building confidence, connecting to and cultivating stewardship of natural world. The students have opportunities to participate in educational sessions, performing arts, and community services. When they are older, they have more opportunities for choices in what modules peaked their interest. In addition, Villani and Atkins (2000) stated that community-based education fosters interdependence and lead towards educational and community practices that have the potential to impact people on a global scale. Moreover, Praveen (2020) explained that community-based curriculum urges students to be more interested in the subjects and concepts being taught, be more inspired to learn if academic study connects to concepts, issues, and contexts that are more familiar, understandable, accessible, or personally relevant to them. The students can improve knowledge retention, skill acquisition, and preparation for adult life because they can be given more opportunities to apply learning in practical, real-life settings by researching, or volunteering to improve the world in some meaningful way. Contents to be taught can be local institutions, history, literature, cultural heritage, and natural environment.

English has been studied as a foreign language (EFL) in Thailand, and a large number of mistakes have been found for about four decades as exemplified by research findings that students taking courses of English aimed to develop their English writing abilities, failed to attain their goals, as Vessakosol (1983) found that the undergraduate students enrolling in the course of English writing I, made errors on lexicon, syntax, and morphology. The most frequent misuses of lexicon were on verbs, syntax on articles, and morphology on tense markers. Sermsook et al. (2017) revealed similar results that Thai EFL students frequently made errors in punctuations, articles, subject verb agreement, spelling, capitalization, and fragments. Those who studied in English major and in an international program, made similar mistakes as Khemtong (1981) studied errors in English writing of English major students studying at Ramkhamhaeng University, and found errors in punctuation, vocabulary and idiom usage, spelling, and grammatical structure, respectively. Moreover, Jenwithisook (2007) found that her juniors of international program studying at Rajamangala University of Technology Siwichai misused of determiners, subject and verb agreement, prepositions, and tenses. The English ability of Thai people in general, compared to those living in non-English speaking countries, was placed at a very low level of the seventy fourth rank out of eighty countries in the world (Posttoday.com, 2019).

Based on the mentioned data, it is urgently required that high school students need to be prepared for efficient communication in English through the curriculum of integration with local communities in meaningful aspects of local institutions, history, literature, cultural heritage, and natural environment.

\section{Method and Material}

\subsection{Research Objectives}

The research objectives were to study needs of high school students and teachers on competency-based curriculum integrated with local community for the high school students, develop a curriculum based on the needs, implement the developed curriculum, and evaluate the developed curriculum.

\subsection{Research Design}

The study was research and development design with the needs study stage followed by the competency-based curriculum development and implementation. Through the implementation stage, the students had a pretest, and then studied 25 subtopics, arranged up to their needs on the topics of cultural heritage, natural environment, local institutions, history, and literature, within 38 hours of 19 weeks and took the posttest. The duration of each subtopic lasted 1-3 hours based on the contents. The main activities of each subtopic were to assign individual student to read the given content for main ideas, then to work in pairs to fill in the incomplete conversations, and 
continue to create at least five sentences of dialogues corresponding to the subtopic by using their own words. Each pair was assigned to perform the conversations while the others reflected for more efficient communication. After the conversation performances, each pair summarized the subtopic, inserted interesting and related pictures, and uploaded them online after feedback from the teacher. The time series of the design illustrated by Table 1

Table 1. Time series of the design

\begin{tabular}{ll}
\hline Topics & Duration \\
\hline Pretest & 1 \\
1. Buddhist Temples in Ubon Ratchathani & 1 \\
2. Nong Pa Pong Temple & 1 \\
3. Candle Festival & 3 \\
4. Lighting Boats in the Mun River at Night & 1 \\
5. Local Boat Racing & 1 \\
6. Magnificent Foods of Ubon Ratchathani & 2 \\
7. Pha Team Ancient Painting Cliff & 2 \\
8. Soi Sa Wan Waterfalls & 1 \\
9. Two-colored Rivers & 1 \\
10. Phu Phrao Temple & 2 \\
11. Sam Pan Boak (Three Thousand Natural Rock Holes) & 2 \\
12. Science Week at Ubon Ratchathani Rajabhat University & 2 \\
13. Ubon Ratchathani University & 1 \\
14. Primary School District of Interest & 1 \\
15. Secondary School District & 1 \\
16. International Schools in Town & 2 \\
17. Tao Kam Phong the Ancestor & 2 \\
18. The Northeast Region Capital & 1 \\
19. The City of Dhama & 1 \\
20. The City of Candle & 2 \\
21. Dong U Pueng the City Location & 2 \\
22. Pha Ya (Ancient Poem of Locality) & 1 \\
23. Mor Lam (Local Singing Songs) & 1 \\
24. Ted Ma Ha Chat (The Buddha Last Birth) & 1 \\
25. Proverbs of the Region & 1 \\
Posttest & 1 \\
\hline
\end{tabular}

According to Table 1, the students spent 3 hours on the subtopic of candle festival, since the city has been worldwide outstanding for the festival, ten contents for 2 hours, and the rests for an hour.

\subsection{Population and Sampling Procedures}

The population consisted of 1175 high school students and 140 teachers at 7 schools located in Ubon Ratchathani, and Warinchamrab Municipalities. The samples of the needs study stage consisted of 244 high school students, and 82 teachers, gained by quota sampling, and the sample for the curriculum implementation consisted of 34 high school students studying at Luekamhan Warinchamrab School, in the second semester of academic year 2018, gained by cluster sampling.

\subsection{Instruments}

The research instruments were a developed curriculum, questionnaires for the students and the teachers, a test of English expression, a test of writing, and an attitude evaluation form. The developed curriculum contained vision and mission to achieve the students' competency through aims, contents of 5 topics with 25 subtopics, the instructional procedures concentrated on practicing, and the evaluation focused on performances. The questionnaires for the students and the teachers included 10 items of a five-point Likert scale concerning needs on local community integration with the competency-based curriculum, the criteria of average scores $(\bar{x})$ were set at 4.50-5.00 mean the highest, 3.50-4.49 mean higher, 2.50-3.49 mean medium, 1.50-2.49 mean lower, and 1.00-1.49 mean the lowest. The test of English expression contained 40 items of multiple choices, it was validated by trying out with 81 high school students at Nareenukul School, and the test reliability coefficient was .96. The attitude evaluation form was also a five-point Likert scale concerning opinions on the developed curriculum, the criteria of average scores $(\bar{x})$ were set at 4.50-5.00 mean the highest, 3.50-4.49 mean higher, 2.50-3.49 mean medium, 1.50-2.49 mean lower, and 1.00-1.49 mean the lowest. The test of writing was to 
assign the students to write a short paragraph about an accustomed picture of Ubon Ratchathani Candle Parade, the criteria of the paragraph writing scoring rubrics were created by applying micro and macro aspects suggested by Ur (1996) as illustrated in Table 2. The speaking scoring rubrics for the conversation performance throughout the curriculum implementation were also created by applying accuracy and fluency aspects suggested by Ur (1996) as illustrated in Table 3. The collected data were analyzed by employing mean, standard deviation, and t-test. The evaluation of writing ability was based on the mastery criteria of 80-100 percent means good, 50-79 percent means fair, and below 50 percent means weak (Reiser et al., 1986).

Table 2. Scoring rubrics for paragraph writing (Total score is 10)

\begin{tabular}{|c|c|c|}
\hline Micro & Scores & Macro \\
\hline Correct spelling, punctuations, collocations, and grammars & 5 & Content and organization are coherent and easy to \\
\hline $\begin{array}{l}\text { An error found even on spelling, punctuations, collocations, and } \\
\text { grammars }\end{array}$ & 4 & $\begin{array}{l}\text { communicate } \\
\text { An error found even on content or organization }\end{array}$ \\
\hline Two to three errors found even on spelling, punctuations, & 3 & Some errors found on content or organization \\
\hline $\begin{array}{l}\text { collocations, and grammars } \\
\text { Four to five errors found even on spelling, punctuations, } \\
\text { collocations, and grammars }\end{array}$ & 2 & Several errors found on content or organization \\
\hline More than 5 errors found & 1 & $\begin{array}{l}\text { Content and organization are not coherent and difficult to } \\
\text { communicate }\end{array}$ \\
\hline
\end{tabular}

Table 3. Scoring Rubrics for conversation performance

\begin{tabular}{|c|c|c|}
\hline Accuracy & Scores & Fluency \\
\hline Little or no language produced & 1 & Little or no communication \\
\hline $\begin{array}{l}\text { Poor vocabulary, mistakes in basic grammar, may have very } \\
\text { strong foreign accent }\end{array}$ & 2 & $\begin{array}{l}\text { Very hesitant and brief utterances, sometimes difficult to } \\
\text { understand }\end{array}$ \\
\hline $\begin{array}{l}\text { Adequate but not rich vocabulary, makes obvious grammar } \\
\text { mistakes, slight foreign accent }\end{array}$ & 3 & Gets ideas across, but hesitantly and briefly \\
\hline $\begin{array}{l}\text { Good range of vocabulary, occasional grammar slips, slight } \\
\text { foreign accent }\end{array}$ & 4 & Effective communication in short turns \\
\hline $\begin{array}{l}\text { Wide vocabulary appropriately used, virtually no grammar } \\
\text { mistakes, native-like or slight foreign accent } \\
\text { Total Score out of } 10 \text { : ------ }\end{array}$ & 5 & Easy and effective communication, uses long turns \\
\hline
\end{tabular}

\section{Results}

The findings revealed that the students and the teachers rated their needs on the curriculum at a higher level, as illustrated in Tables 4 and 5, the developed curriculum contained vision, mission to achieve the students' competency through the aims, contents, and instructional procedures concentrated on practicing and the evaluation focused on performances, the students had significantly higher learning achievement and writing skills after the curriculum implementation than those before the implementation at the level .01., as illustrated in Tables 6 and 7, it was also found that the conversation performance throughout the curriculum implementation was at fair level as a whole, as illustrated in Table 8 , and the developed curriculum was evaluated by the students at medium level of its feasibility, as illustrated in Table 9.

Table 4. The needs of the students $(n=244)$

\begin{tabular}{|c|c|c|c|c|}
\hline Item & Needs & $\bar{x}$ & SD. & Meaning of $\bar{x}$ \\
\hline 1 & You need to learn about local community to develop your English skills. & 4.65 & .54 & Highest \\
\hline 2 & You need to communicate with foreigners about your local community & 4.66 & .53 & Highest \\
\hline 3 & You need to acquire knowledge about your local community & 4.65 & .53 & Highest \\
\hline 4 & You need to disseminate about your local community worldwide & 4.27 & .50 & Higher \\
\hline 5 & $\begin{array}{l}\text { You agree to the idea of learning about local community is better than learning other } \\
\text { contents }\end{array}$ & 4.23 & .48 & Higher \\
\hline 6 & You believe that learning about local community is related to your real life & 4.22 & .47 & Higher \\
\hline 7 & You accept that learning about local community makes you more interested in English & 4.22 & .48 & Higher \\
\hline 8 & You believe that learning about local community inspires you to learn English & 4.22 & .47 & Higher \\
\hline 9 & You believe that learning about local community makes you understand more contents & 4.22 & .47 & Higher \\
\hline \multirow[t]{2}{*}{10} & $\begin{array}{l}\text { You believe that learning about local community gives opportunities to conduct surveys and } \\
\text { services }\end{array}$ & 4.22 & .47 & Higher \\
\hline & Total & 4.36 & .42 & Higher \\
\hline
\end{tabular}


According to Table 4, the mean score of the students' needs was 4.36, which was at a higher level as a whole.

Table 5. The needs of the teachers $(n=82)$

\begin{tabular}{lllll}
\hline Item & Needs & $\bar{x}$ & SD. & Meaning of $\bar{x}$ \\
\hline 1 & The students need to learn about local community to develop their English abilities & 4.03 & .48 & Higher \\
2 & The students need to communicate with foreigners about their local community & 4.71 & .52 & Highest \\
3 & The students need to acquire knowledge about local community & 4.74 & .49 & Highest \\
4 & The students need to disseminate about local community worldwide & 4.74 & .49 & Highest \\
5 & Learning about local community is more useful compared to other contents & 4.24 & .48 & Higher \\
6 & Learning about local community is related to the students' real life & 4.54 & .56 & Highest \\
7 & Learning about local community helps the students more interested in English & 4.23 & .47 & Higher \\
8 & Learning about local community inspires the students to learn English & 4.30 & .55 & Higher \\
9 & Learning about local community helps the students understand more contents & 4.66 & .51 & Highest \\
10 & Learning about local community gives opportunities to the students to conduct surveys & 4.17 & .43 & Higher \\
& and services & & & Higher \\
\hline
\end{tabular}

According to Table 5, the mean score of the teachers' needs was 4.44, which was at a higher level, as a whole.

Table 6. The students' learning achievement $(n=34)$

\begin{tabular}{llll}
\hline Score (Total 40) & $\bar{x}$ & SD. & t-value \\
\hline Pretest & 10.14 & .53 & $24.38^{* *}$ \\
\cline { 1 - 3 } Posttest & 13.61 & .55 & \\
\hline
\end{tabular}

Note. $* * \mathrm{p} \leq .01$.

According to Table 6, the mean score of the pretest was 10.14, while the mean score of the posttest was 13.61, with the $t$-value of 24.38 , showed significantly higher of the posttest than that of the pretest at the .01 .

Table 7. The students' writing skills $(\mathrm{n}=34)$

\begin{tabular}{llll}
\hline Score (Total 10) & $\bar{x}$ & SD. & t-value \\
\hline Pretest & 1.83 & 1.02 & $18.19^{* *}$ \\
\cline { 1 - 3 } Posttest & 3.69 & 1.18 & \\
\hline
\end{tabular}

Note. $* * \mathrm{p} \leq .01$.

According to Table 7, the mean score of pretest writing skills was 1.83 , while the posttest was 3.69 , with the $\mathrm{t}$-value of 18.19 , showed significantly higher of the posttest than that of the pretest at the .01 .

Table 8. The conversation performance $(\mathrm{n}=17)$

\begin{tabular}{lllll}
\hline Item & Performance & $\bar{x}$ & SD. & Meaning of $\bar{x}$ \\
\hline 1 & Conversations concerning cultural heritage & 5.88 & .85 & Fair \\
2 & Conversations concerning natural environment & 6.82 & .52 & Fair \\
3 & Conversations concerning local institutions & 7.00 & .00 & Fair \\
4 & Conversations concerning local history & 6.94 & .24 & Fair \\
5 & Conversations concerning local literature & 7.58 & .50 & Fair \\
& Total & $\mathbf{6 . 8 4}$ & $\mathbf{. 1 9}$ & Fair \\
\hline
\end{tabular}

According to Table 8, the students' conversation performances on cultural heritage, natural environment, local institutions, history, and literature throughout the curriculum implementation were at fair level as a whole, with the mean score of 6.84 . 
Table 9. The developed curriculum evaluation $(n=34)$

\begin{tabular}{lllll}
\hline Item & List of evaluation & $\bar{x}$ & SD. & Meaning of $\bar{x}$ \\
\hline 1 & Learning about local community helps improve your English & 3.00 & .00 & Medium \\
2 & Learning about local community is better than learning other contents & 4.00 & .00 & Higher \\
3 & Learning about local community encourages you more confident to communicate with & 4.00 & .00 & Higher \\
& foreigners & & & \\
4 & Learning about local community helps you acquire more knowledge & 5.00 & .00 & Highest \\
5 & Learning about local community helps you gain contents for communication & 4.00 & .00 & Higher \\
6 & Learning about local history is helpful for communication & 1.50 & .50 & Lower \\
7 & Learning about local literature is helpful for communication & 1.50 & .50 & Lower \\
8 & Learning about cultural heritage is helpful for communication & 1.47 & .50 & Lowest \\
9 & Learning about local natural environment is helpful for communication & 3.00 & .00 & Medium \\
10 & Learning about local institutions is helpful for communication & 4.00 & .00 & Higher \\
11 & Learning about local community is practical in real contexts & 3.11 & .32 & Medium \\
12 & Learning about local community gives you opportunities to learn with local wisdom & 5.00 & .00 & Highest \\
13 & Learning about local community helps you create new products & 1.29 & .46 & Lowest \\
14 & Learning about local community helps you preserve natural resources & 4.00 & .00 & Higher \\
15 & Learning about local community helps you develop it & 4.00 & .00 & Higher \\
& Total & $\mathbf{3 . 2 5}$ & $\mathbf{. 0 9}$ & Medium \\
\hline
\end{tabular}

According to Table 9, the students rated the developed curriculum at medium level as a whole, with the mean score of 3.25 .

\section{Discussion}

According to the first research objective, the result indicated the students and the teachers rated their needs for competency-based curriculum at a higher level with the mean scores of 4.36, and 4.44. These might have been because they recognized the aim of Thailand Educational Act of 1999 in the aspect of curriculum implementation or the teaching learning process that the teachers needed to change the teacher-centered method of teaching to the preferable student-centered ones. Base on the characteristics of competency-based curriculum, as mentioned, focus on practices, referred to skills and ability to apply acquired knowledge through various tasks. Therefore, the students and the teachers needed a new learning procedure commonly called active learning as specified by Prince (2004) that an active learning means any instructional method that engages students in the learning process, requires students to do meaningful learning activities, and think about what they are doing.

The developed curriculum contained vision, mission to achieve the students' competency through the aims, contents, instructional procedures concentrated on practicing, the evaluation focused on performances, helped the students gain significantly higher learning achievement and writing skills after the curriculum implementation than those before the implementation at the level .01. These might have been because the nature of learner-centered activities, and the tasks assigned the students to work cooperatively throughout the learning session, brought the positive results as confirmed by Batool (2012), Altun (2015), and Parveen et al. (2017) which found a similar finding that cooperative learning showed better results for student scholastic accomplishment. Moreover, Andrea and Trivino (2016) conducted a research to see whether cooperative learning can foster the development of adolescents' English writing skills, and the result indicated the subjects performed greater development in English writing.

The developed curriculum was evaluated by the students at medium level of its feasibility, throughout the implementation stage, which indicated the positive result. This might have been because they advocated that learning about local community helped them comprehend the contents and was usefulness in their real life, as confirmed by Ibrahim (2010) that community-based learning impacted academics, critical thinking skills, communication ability, inter-personal skills, local and global citizenship, and intra-personal development. Nnamani and Ovibe (2015) also confirmed that community-based instruction provided students cross-cultural learning experience. Moreover, Kim (2015) concluded that competency-based curriculum was effective, sustainable and can be customized to address the skill gaps in the rapidly evolving information professions.

\section{Conclusion and Recommendations}

The developed English competency-based curriculum with vision, mission to achieve the students' competency through the aims, contents, and instructional procedures concentrated on practicing and the evaluation focused on performances helped the students gain significantly higher learning achievement and writing skills after the curriculum implementation, and it was evaluated by the students at medium level of its feasibility. 
Recommendations for English teachers who like to apply the competency-based procedures, need to combine the three aspects of knowledge, skills, and attitude through appropriate community contents, focus on assignments of cooperative work, conversation performances, and reflections for improvement before uploading online the summary of each subtopic illustrated with some pictures, or video clips. Through the online uploading process, the students need to survey, work with, or ask for help from people living in the community to make their upload more lively and authentic, which will bring interaction between schools and communities. For the assessment, the competence behaviors used as measurable indicators of learning progress must be identified on the agreement between students and teachers.

\section{Acknowledgement}

I would like to sincerely thank Ubon Ratchathani Rajabhat University for the supporting research budget, the subjects including the students and the teachers, especially those for trying out the instruments, and the curriculum implementation. Grateful thanks to the coordinators in the stages of needs assessment, and the curriculum implementation.

\section{References}

Altun, S. (2015). The Effect of Cooperative Learning on Students' Achievement and Views on Science and Technology Course. International Electronic Journal of Elementary Education, 7(3), 451-468.

Andrea, P., \& Trivino, C. (2016). Using Cooperative Learning to Foster the Development of Adolescents' English Writing Skills. Teachers' Professional Development, 18(1), 21-38. https://doi.org/10.15446/profile.v18n1.53079

Andronachea, D., Bocosb, M., \& Neculaue, B. C. (2015). A Systematic-interactionist Model to Design a Competency-based Curriculum. Procedia-social and Behavioral Sciences, 180(5), 715-721. https://doi.org/10.1016/j.sbspro.2015.02.183

Answer Programs. (2020). Community Based Curriculum (CBC). Retrieved January 12, 2020, from https://www.answercharterschool.org/

Batool, S. (2012). Effect of Cooperative Learning on Achievement of Students in General Science at Secondary Level. International Education Studies, 5(2), 154-158. https://doi.org/10.5539/ies.v5n2p154

Chambers, D. W. (1993). Toward a Competency-Based Curriculum. Journal of Dental Education, 57(11), 790-793. https://doi.org/10.1002/j.0022-0337.1993.57.11.tb02806.x

Ibrahim, M. (2010). The Use of Community Based Learning in Educating College Students in Midwestern USA. Procedia - Social and Behavioral Sciences, 2(2), 392-396. https://doi.org/10.1016/j.sbspro.2010.03.032

Jenwithisook, T. (2007). A Study of Persisted Errors in Writing of the Third Year Students of English for an International Communication Program. Research Report. Rajamangala University of Technology Siwichai.

Khemtong, P. (1981). A Study of Errors in Written English of Ramkhamhaeng English Teaching Major Students. Research Report. Ramkhamhaeng University.

Kim, J. (2015) Competency-based Curriculum: An Effective Approach to Digital Curation Education. Journal of Education for Library and Information Science, 56(4), 283-297. https://doi.org/10.3138/jelis.56.4.283

Nikolov, R., Shoikova, E., \& Kovatcheva, E. (2014). Competence Based Framework for Curriculum Development. Sofia; Za bukvite, O'pismeneh.

Nillapun, M., Phivitayasirithum, C., Vanichwatanavorachai, S., \& Songserm, U. (2015). Evaluation of the Basic Education Core Curriculum 2008 in the Leading Schools for Curriculum Implementation. Journal of Silpakorn Educational Research, 7(1), 22-41.

Nnamani, V. S., \& Ovibe, O. A. (2015). Impact of Community-Based Instruction on Implementation of Social Studies Curriculum in Secondary Schools in Abakaliki Education Zone of Ebonyi State. Journal of Humanities and Social Science, 20(9), 4-9.

Office of the National Education Commission, Office of the Prime Minister, Thailand. (2008). Education in Thailand 2007. Bangkok, Amarin Printing and Publishing.

Parveen, Q., Yousuf, M. I., \& Mustafa, S. (2017). An Experimental Study on the Effect of Cooperative Learning on Students' Academic Achievement and Students' Perceptions towards Cooperative Learning. The Anthropologist, 27(1-3), 69-76. https://doi.org/10.1080/09720073.2017.1311670

Posttoday.com. (2019). English ability of Thai People consecutively three-year dropped at the seventy fourth 
rank of the world. Retrieved November 6, 2019, from http://www.posttoday.com

Praveen, C. (2020). Community-based Curriculum. Retrieved January 12, 2020, from http://www.newrootschool.org/

Prince, M. (2004). Does Active Learning Work? A Review of the Research. Journal of Engineering Education, 93(3), 223-231. https://doi.org/10.1002/j.2168-9830.2004.tb00809.x

Reiser, R. A., Driscoll, M. P., Farland, D. S., Vergara, A., \& Tessmer, M. C. (1986). The Effects of VariousMastery Criteria on Student Performance and Attitude in a Mastery-Oriented Course. Educational Technology Research and Development, 34(1), 31-38.

Sermsook, K., Liamnimitr, J., \& Pochakorn, R. (2017). An Analysis of Errors in Written English Sentences: A Case Study of Thai EFL Students. English Language Teaching, 10(3), 101-110. https://doi.org/10.5539/elt.v10n3p101

Ur, P. (1996). A Course in Language Teaching. Cambridge: Cambridge University Press.

Vessakosol, P. (1983). English Writing Abilities of Undergraduate Students Enrolling in English Writing I. Research Report. Thammasat University.

Villani, C. J., \& Atkins, D. (2000). Community-Based Education. School Community Journal, 10(1), 121-126.

\section{Copyrights}

Copyright for this article is retained by the author, with first publication rights granted to the journal.

This is an open-access article distributed under the terms and conditions of the Creative Commons Attribution license (http://creativecommons.org/licenses/by/4.0/). 